\title{
Moving beyond the concept of altered state of consciousness: the Non-Ordinary Mental Expressions (NOMEs)
}

\section{Enrico Facco ${ }^{1,2,3}$, Fabio Fracas ${ }^{3,4}$, and Patrizio Tressoldi ${ }^{3,5}$}

\author{
${ }^{1}$ Studium Patavinum - Dept. of Neurosciences, University of Padua, Italy \\ ${ }^{2}$ Inst. Franco Granone - Italian Center of Clinical \& Experimental Hypnosis, Turin, Italy \\ ${ }^{3}$ Science of Consciousness Research Group - Dept. of General Psychology, University of Padua, \\ Italy \\ ${ }^{4}$ Scientific Associate at CERN, Geneva, Switzerland \\ ${ }^{5}$ Dept. of General Psychology, University of Padua, Italy \\ [A shorter version of this paper has been published \\ on Advances in Social Sciences Research Journal, 8(3) 615-631. \\ https://journals.scholarpublishing.org/index.php/ASSRJ/article/view/9935]
}

Corresponding author

Patrizio Tressoldi

Email: patrizio.tressoldi@unipd.it 


\begin{abstract}
Aim of this theoretical paper is to review the ontological status of so-called altered states of consciousness, suggesting a revision of their common interpretation as abnormal, or anyway lessthan-normal conditions. The term Non-Ordinary Mental Expressions (NOMEs), is described and emphasized as a new conceptual tool allowing a more comprehensive interpretation of the varieties of the normal albeit non ordinary consciousness experiences and their implications in the mindbody relationship.
\end{abstract}

Keywords: consciousness; altered states; non-ordinary mental expressions; epistemology 


\section{Introduction}

Uncommon or exceptional, hardly explainable experiences and the encounter with the "Unknown" have intrigued and challenged peoples, philosophers, priests, artists and physicians since the prehistory in all cultures, engendering a profound influence in the weltanschauung (view of the world), the spirituality and the cultural development of the whole humanity. Shamans (the term means "man of knowledge") of all ages have probed the reality as a whole - including the visible and the invisible, what is at the boundaries between ordinary and non-ordinary experience or is seemingly placed beyond it - in order to comprehend the relationship between man, Nature and reality, the meaning of life and death, as well as to take care and heal diseased people.

Both Eastern and Western philosophies stem from a common core, the prehistoric pan-Asiatic shamanism, from which ancient medicine developed as well - traditional Chinese medicine and acupuncture in Taoism, ayyrveda medicine (the term means, knowledge of life) in Veda tradition,

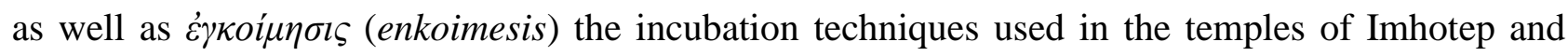
Asclepius in ancient Egypt and Greece, respectively (Facco, 2014; Facco \& Tagliagambe, 2020). Incubation can be considered as the first form of hypnosis used in ancient medicine as a psychosomatic procedure able to favor recovery and a valuable analgesic allowing for surgery. Even Parmenides, the great philosopher of the Being and Nihil - named by Plato "Venerable and Awesome" in the Theaetetus (183e) - was also iatros (physician), iatromantis (healer), expert in incubation and founder of the medical Eleatic school (Facco \& Tagliagambe, 2020; Kingsley, 1999; Vecchio, 2004).

The concept of altered states of consciousness (ASC) has been introduced in medicine by Ludwig in 1966 in a review encompassing both the physiological and pathological ones with the aim to describe their common aspects and denominators, and the conditions necessary for their emergence. He wisely emphasized the risk of conceptual pitfalls in his general approach, as well as the (at least partly) artificial nature of any classification and concluded that "many ASC serve as final common pathways for many different forms of human expression, both maladaptive and adaptive". Later on, ASCs have been classified from a strictly neurophysiological and psychobiological perspective ( Boveroux et al., 2008; Vaitl et al., 2005), while other authors have also suggested the need for a revision of the very concept of ASC (Revonsuo, Kallio, \& Sikka, 2009).

In short, ASCs are a huge, complex and intriguing topic, which has accompanied the humankind since time immemorial. As such, they are a relevant part of the physiology of mind, the proper comprehension of which involves a multidisciplinary and metaphilosophical approach encompassing their meanings as well as their deep, inescapable epistemological implications. The aim of this article is to reappraise and, hopefully, help overcoming the concept of ASC as it has been conceived from a narrow psychobiological perspective and differentiate physiological Non-Ordinary Mental Expressions (NOMEs), from pathological ASCs, in order to avoid a misleading overlapping. In fact, their possible commonalities, as emphasized by Ludwig himself, are useful to check the relationship between physiology and pathology, but the ruling positivist stance adopted by medicine has been too easily inclined to equate what is ostensibly odd to "altered", i.e., a dysfunctional or pathological phenomenon.

\section{About ASCs}

Ludwig defined ASCs as "any mental state(s) induced by various physiological, psychological, or pharmacological maneuvers or agents, which can be recognized subjectively by the 
individual himself (or by an objective observer of the individual) as representing a sufficient deviation in subjective experience or psychological functioning from certain general norms for that individual during alert waking consciousness" (Ludwig, 1966). His classification included five groups of causes or triggers (see Table 1) and mentioned a wide range of possible ASCs without systematically framing them in a structured list.

Table 1: Classification of ASCs according Ludwig (1966).

\begin{tabular}{l}
\hline CAUSES \\
\hline A. Reduction of exteroceptive stimulation \\
and/or motor activity \\
B. Increase of exteroceptive stimulation \\
and/or motor activity \\
C. Increased alertness or mental \\
involvement \\
D. Decreased Alertness or Relaxation of \\
critical faculties \\
E. Presence of somatopsychological \\
factors
\end{tabular}

He held an open-minded approach - contemplating a wide range of ASCs (also mentioning the incubation techniques in ancient Egypt and Greece) and looking for possible commonalities between different ASCs - a fact also witnessed by taking LSD for experimental purposes in order to check the effects on himself.

In 2005 the ASC Consortium, an European institution founded in 1998 with the aim to conceptualize and systematically explore ASCs in the context of neurosciences, has classified ASCs adopting empirical-descriptive criteria as a base to develop an ASC model (Vaitl et al., 2005); however, to our knowledge, the ASC Consortium has not published anything since then. The authors have classified ASCs according to their origin - i.e., spontaneous, induced, or pathological - (see Table 2) and, after a short description including phenomenal features and their possible neurocorrelates, draw the following conclusions:

1. Spontaneous ASCs seem to be related to transient cortical activity and arousal changes and "vanish when the central arousal system returns to normal levels either by voluntary control, biological rhythms (sleep-wake cycles), or resuscitation".

2. Physical and physiological factors have a huge impact on brain functions, leading to different experiences related to the surplus or deficit of energy to the brain.

3. The wealth of available data on psychological procedures of induction allows to develop new functional models of ASC changes of consciousness and cognition and experimental methods to test them.

4. Pathological processes yielding ASCs involve different ways of affecting brain function, which seem to be organized in hierarchical levels, given that the stream of consciousness depends on integrated and coherent neural processes. Their pathological changes also hold the concept of neurobiological modularity, the nature of which remains broadly unknown yet. 
5. Brain activation seems to be an essential factor for both awareness and behavior. The former may range from a narrow, focused attention to a broadest extended form of contemplation of all things and from forgetting oneself to an intensified feeling of one's unique being. Likewise, the sensory dynamics may range between two opposite poles, e.g., from anesthesia to hypersensitivity, and may yield perceptions unrelated to appropriate physical stimuli.

Table 2: Classification of ASCs according to the ASC Consortium (Vaitl et al., 2005)

\begin{tabular}{|c|c|}
\hline Origin & $\mathbf{A S C}$ \\
\hline Spontaneous & $\begin{array}{l}\text { Drowsiness } \\
\text { Daydreaming } \\
\text { Hypnagogic states } \\
\text { Sleep } \\
\text { Dreaming } \\
\text { Near-death experiences }\end{array}$ \\
\hline Environmental factors & Extreme environmental conditions \\
\hline Physiological factors & $\begin{array}{l}\text { Starvation } \\
\text { Sexual activity and orgasm } \\
\text { Respiratory maneuvers } \\
\text { Fasting }\end{array}$ \\
\hline Psychological factors & $\begin{array}{l}\text { Sensory deprivation or overload } \\
\text { Rhythm-induced trance (e.g., shamanic drum, } \\
\text { twirling Dervishes) } \\
\text { Relaxation } \\
\text { Meditation } \\
\text { Hypnosis } \\
\text { Biofeedback }\end{array}$ \\
\hline Neurological or psychiatric diseases & $\begin{array}{l}\text { Psychosis } \\
\text { Coma } \\
\text { Vegetative State } \\
\text { Epilepsy }\end{array}$ \\
\hline
\end{tabular}

Likewise Ludwig (1966), Vaitl et al (2005) gathered pathological and non-pathological ASCs in a whole. However, their list of ASCs is largely incomplete. For example, the author did not include the ASCs induced by psychotropic drugs, while the list of those caused by brain injuries was 
largely incomplete [the reader can find a detailed analysis of them in the seminal work by Plum and Posner Stupor and Coma (1980)]. In our opinion, the most relevant authors' conclusion is the acknowledgement that most ASC features may be detected only from a first person perspective (1PP) - i.e., from subjects' narration of their experience. This implicitly acknowledges the limits of the ruling positivist-objectivist stance of medical science in the understanding of subjective phenomena; on the other hand, the analysis and conclusions of Vaitl et al. (2005) remain solidly based on such a perspective. The same goes for the article by Boveroux et al. (2008), where the authors took into account only a limited number of ASCs (sleep, general anesthesia, coma and vegetative state) from a strictly neurobiological reductionist perspective. The mentioned ASCs were again classified according to their origin and were conceived as physiologically, pharmacologically, and pathologically altered conscious states, marked by regional and/or global changes of brain metabolism. Their analysis, despite useful in the assessment of some brain mechanisms associated to different ASCs, is far from providing an appropriate outline of their huge variety and meaning. Later on, the traditional concept of ASC has been questioned (Revonsuo et al., 2009), emphasizing the fact that an ASC does not depend on a plain alteration of perception or consciousness per se; rather, it is marked by changes of the informational or representational relationships between consciousness and the world, i.e., a matter of misinterpretation. Interestingly, they emphasized that, unlike Ludwig definition, one may not be aware of one's own ASC; this is certainly true for pathological ASCs but it may occur only in selected cases of non-pathological ones, like the spontaneous experience of other identities in deep hypnosis, followed by a post-hypnotic amnesia (Facco, Mendozzi, et al., 2019). On the other hand, the authors still kept the view of ASCs as a heterogeneous mix of physiological and pathological phenomena, with the implicit inclination to consider all ASCs as an expression of a dysfunctional, pathologic, or anyway less-than-normal condition with respect to ordinary consciousness.

The above-mentioned classifications of ASCs, despite useful as a first attempt to investigate and understand this intriguing topic, may be misleading for two main reasons: a) merging in a whole physiological and pathological conditions, strongly risks to a priori take all what is non-ordinary for dysfunctional, given their ostensible oddity with respect to the adopted weltanschauung; b) the ruling monist materialist stance of mainstream neuroscience and the mechanist-reductionist approach were born to investigate the physical reality only and, alone, are not suitable to properly comprehend the world of subjectivity. In other worlds, the problem of ASCs is endowed with the same huge epistemological and metaphysical implications involved in the foundation of the science of consciousness and the definition of the Self (Facco, Al khafaji, \& Tressoldi, 2019; Facco \& Fracas, 2018; Facco, Lucangeli, \& Tressoldi, 2017; Tressoldi, Facco, \& Lucangeli, 2017). Therefore, it is advisable to take a critical look encompassing their previous description as well as the very concept of ASC and, hopefully, move beyond it. Here, we shall shortly analyze the data reported by Vaitl et al. (2005) seeking for possible pitfalls; then, the field of the NOMEs will be described and shortly analyzed in its general aspects and, finally, the main physical and epistemological implications will be synthetically discussed.

\section{The problem of origin}

Classifying ASCs according to their triggers, is misleading since specific stimuli able to exclusively yield a given ASC do not exist, while different ASCs may share common elements or may even greatly overlap in a common picture. For example, Near-death experiences (NDEs) have been 
considered as spontaneous events by the ASC Consortium. Instead, they are triggered by a wide range of different critical and non-critical events of both physical and psychological nature (NDElike experiences) - the former involving a loss of consciousness and the latter including existentially critical conditions, like role transitions (Charland-Verville et al., 2014; Facco \& Agrillo, 2012b, 2012a; Facco, Agrillo, \& Greyson, 2015). Furthermore, some triggers cannot be considered only as physical stimuli able to alter brain function per se without taking into account their intentional use and control by the subject.

\section{Sleep and dream}

Deep sleep and dream have been so far considered as ASCs, a fact revealing a naïve empirical approach based on, a), the common sense and the inclination to check differences as they appear to the ordinary consciousness, and, b) the Western traditional inclination to consider wakefulness superior to sleep. If it is undeniable that sleep is phenomenally different from wakefulness, it seems meaningless to separate the two conditions. In fact, we spend about one third of our life sleeping and incessantly shift between different levels of arousal, awareness, light and deep sleep, and dream. Therefore, it seems more correct considering them as an inseparable, functional, dynamic whole, rather than separating and substantializing them as ontologically different states. As a matter of facts, sleep is essential for life and a healthy consciousness, where a non-stop exchange of information between consciousness and the unconscious occurs, involving also a fruitful non-stop processing of information during sleep (Dijksterhuis \& Nordgren, 2006; Ritter \& Dijksterhuis, 2014). Furthermore, the wakefulness-sleep cycle is embedded in the chronobiologic regulation and the natural rhythm of night and day. As a result, dealing with sleep as an ASC, looks like considering the night as an altered state of the day. It would be a meaningless definition stemming from the naïve perception of consciousness as the foundation of man, weirdly switched off by sleep and, as such, equated to a sort of temporary death, as well painted by Shakespeare in the Hamlet (Act III, Scene I): "To die - to sleep, No more; and by a sleep to say we end the hearthache... To die, to sleep; to sleep, perchance to dream-ay, there's the rub".

\section{Fasting}

Physiological stimuli like fasting may certainly alter the state of consciousness triggering illusions and hallucinations in anorexic patients, but fasting may also be the result of an intentional choice with its deep motivations and spiritual implications. It is a transcultural practice since time immemorial, practiced by ascetics and mystics and contemplated as a ritual practice by most, if not all religions, in order to enhance the control on one's drives, mind and body on the way of selfcontrol and the development of Self, up to the level of sanctity and enlightenment. Siddharta Gautama underwent a six-year long period of ascetic practice, at the end of which he discouraged the use of extreme fasting, since it may affect mental clarity. In Christian tradition, Jesus's fasting in the desert was an essential part of self-control and the liberation from the ego, allowing to triumph over the evil (Matthew 4, 1-2; Luke 4, 1-2), while short-lasting periods of abstinence and fasting are contemplated by all religions of the monotheistic tradition.

The so-call Anorexic Saints, like St. Catherine of Siena and St. Teresa of Avila, practiced extreme forms of fasting. Therefore, the problem of fasting cannot be properly comprehended from a narrow objectivistic neurobiological stance skipping all what is beyond brain circuitry or a classical psychoanalytic perspective focusing on psychodynamic aspects only. In the case of saints, 
psychoanalysis may certainly help investigating the biographical and psychosocial aspects of the anorexia (related to the female condition of their epoch), but the spiritual dimension and, in general, the relevance of Self transformation on the way of enlightenment and sanctity cannot be neglected from both religious and secular perspectives (Facco, Al Khafaji, et al., 2019; Madden, 1994). Therefore, considering fasting only in its physical, neurobiological and psychodynamic aspects may be misleading.

\section{Breathing}

The role of breathing and its control play a role of paramount importance in both Eastern meditation techniques and in mystic currents of the Abrahamic tradition, a fact extending far beyond the limited though relevant physical aspect of $\mathrm{CO}_{2}$ and $\mathrm{pH}$ changes as a trigger of ASCs. Breath control in Yoga and Buddhist meditation ranges from the prānāyama (the control of breathing rhythm), to kumbhaka (the prolonged arrest of breathing), to the awareness and monitoring of breathing without any voluntary control (e.g., in Vipaśyanā - pali Vipassana - meditation). Likewise, several exercises of Chinese Qigong and Tàijíquán as well as Hatha Yoga call for a synchronization with breathing (Facco, 2014, 2017). In the Christian mystic tradition, the close relationship between breathing rhythm, emotion and feeling was well known. A calm breathing was associated to a calm mind; in Hesychasm the inspiration corresponded to the reception of the Divine Spirit and the expiration to the withdrawal of the Ego, while arrest of respiration (at the end of each respiratory phase) corresponded to a suspension of ordinary life - to the boundary between life and death, the divine and the human, a sort of being dead in the world: "alive, yet not alive", as St. Paul said (Meister Eckhart, 2012).

\section{Spontaneous, physiological and/or occurring in extreme environmental conditions}

Most if not all extreme environmental conditions are critical and stressful, but they do not play specific, different roles in the alteration of consciousness. For example, natural or man-made disasters, exposure, etc. may yield dissociative experiences or NDE, which have been considered as spontaneous in the ASC Consortium classification; likewise, sensory deprivation may occur in the context of extreme environmental conditions, such as being imprisoned in a cave or down a well or a mine. Relaxation, hypnosis and meditation are relevant intentional introspective activities, which, as such, are not "spontaneous" and share nothing with environmental critical conditions. Indeed, in the Íśvaragìtā (XI, 47-49) - an ancient Sanskrit text belonging to the Kürma Purāṇa - the appropriate and inappropriate places for a fruitful meditation are carefully described and exclude any uncomfortable or unpleasant setting, while their physiological nature as well as the intentional use of breathing control make any distinction between physiological and psychological factors specious. Indeed, even in such critical environmental conditions meditation may help keeping a better self-control and better managing one's resources, thus improving one's chances of survival. It happened in June 2018 to the 12 Thai boys who were trapped in the flooded cave of Tham Luang (province of Chiang Rai, Thailand) for 18 days. Their soccer coach Ekapol Chanthawong, who previously underwent a ten-years training in meditation as a Buddhist monk, taught them to meditate in order keep calmer and remain in full control during the long-awaited rescue. 


\section{From ASCs to Non-Ordinary Mental Expressions (NOMEs)}

In his seminal work, Ludwig correctly gathered physiological and pathological ASCs, given his aim to check their possible common aspects. On the other hand, this mix has implicitly led other authors to equate non pathological ASCs to abnormal, or anyway less-than-normal conditions: this is a misleading conclusion based on nä̈ve realism and the adopted weltanschauungg, which leads to what is ostensibly placed beyond it being a priori taken for abnormal. As previously emphasized, the term "altered" is ambiguous, since it may mean either modified, different, or disordered, while in domestic animals it may mean castrated or spay (Facco et al., 2015). As a result, the term "altered" has created more confusion than clarity, especially when both pathological and nonpathological conscious experiences and mind activities are merged in a whole, implicitly reinforcing the idea of something going wrong.

Besides linguistic ambiguities, the concept of ASC is conceptually problematic because it depends on the definition of normality, a topic endowed with huge uncertainties. The concepts of normality and disease are statistical and conventional in nature: they closely dependent on the adopted paradigm and the available knowledge at any given time (Facco, Casiglia, Zanette, \& Testoni, 2017). When subjective phenomena are concerned, the uncertainty strongly increases, because all terms defining the inner world are much less defined than those indicating physical objects. As a result, a clear-cut exhaustive definition of consciousness is not available yet (and perhaps it will never be); likewise, other related concepts, such as the Self, have a wide range of meanings. Their meaning may in turn be limited or even distorted by specific philosophical, psychological and/or religious stances, while their proper comprehension calls for an interdisciplinary and metaphilosophical approach overcoming the usual ego centered, ethnocentric and chronocentric perspective (Facco, Al Khafaji, et al., 2019; Facco \& Fracas, 2018; Facco, Lucangeli, et al., 2017). Furthermore, ordinary consciousness is diachronic and dependent on sociocultural factors, as emphasized by Julian Jaynes (Jaynes, 1990, 2014), while the identity remains an unresolved conundrum yet (Facco, Al khafaji, et al., 2019). As a result, some ASCs like visions, prophecies, and premonitory dreams were normal and even welcome facts in ancient times, while they are taken for odd, dysfunctional or even psychiatric symptoms in the modern era ruled by monist materialism (a metaphysical stance anyway).

The concepts of normality, disorder and disease are endowed with relevant theoretical and practical implications, being mainly based on statistical assumptions and being at least partly conventional in nature; they are even more evasive when subjective symptoms and psychiatric disorders are concerned (Banzato, Mezzich, \& Berganza, 2005; Berganza, Mezzich, \& Pouncey, 2005; Facco, Casiglia, et al., 2017). Nevertheless, the ruling positivist inclination of medicine has yielded a sort of faith in the distinction between normality and pathology, where psychiatric disorders have been mainly defined as individual neurobiological disorders from a mechanistic-reductionist perspective. The belief in the universal value of such definitions and related management criteria may harm suffering people, when applied tout court to other cultures (Watters, 2011), while the adoption of too strict definitions and diagnostic criteria may lead to normal subjects being wrongly taken for pathological (Frances, 2014).

To summarize, the very concept of normal consciousness is ill defined at best, mostly referring to what implicitly appears to be the prevailing condition of ordinary people. Being the boundaries of normality undefined, non-ordinary states of the mind are likely to be misunderstood, with a high risk to classify as a disorder what is not (Wakefield, 2010). Thus, it is more reasonable to refrain 
from seeking for a clear-cut limit between normality and pathology, and accept a wide grey area in between, where ostensibly odd but non-pathological experiences may occur - taking into account that oddity is conventional in nature, closely depending on the zeitgeist (the spirit of the times) and the adopted metaphysics (Facco, Mendozzi, et al., 2019). This is the case of NOMEs, which do not call for any treatment but, rather, for being properly understood, instead of judging them from a narrow objectivistic mechanist-reductionist approach.

It seems more appropriate to approach ASCs reappraising the wise definition of consciousness by William James: "It is that our normal waking consciousness, rational consciousness as we call it, is but one special type of consciousness, whilst all about it, parted from it by the filmiest of screens, there lie potential forms of consciousness entirely different. We may go through life without suspecting their existence; but apply the requisite stimulus, and at a touch they are there in all their completeness, definite types of mentality which probably somewhere have their field of application and adaptation. No account of the universe in its totality can be final which leaves these other forms of consciousness quite disregarded" (James, 1917, p. 111).

In the process of revision of ASCs, Cardeña, Lynn J., \& Krippner $(2004,2014)$ have introduced the concept of anomalous experience (AE), emphasizing the non-pathological nature of some uncommon, spontaneous experiences differing from the so-called normal ones. AEs are distinct from ASCs since they indicate a series of non-pathological experiences (such as synesthesias) which do not imply an ASC, despite they may share a partial overlapping with them (see Table 3).

Table 3: Anomalous experiences according to Cardeña, Lynn \& Krippner (2014)

Synesthesias
Hallucinatory experiences
Lucid dreaming
Near-death experiences
Mystical experiences
Previous lives memories
Anomalous self and identity experiences
Alien abduction experiences
Psi-related experiences
Anomalous healing experiences

Hypnosis and meditation are not included in the AEs for two reasons: a) they may not yield unusual experiences; b) they are intentional procedures, rather than spontaneously occurring experiences. All AEs, insofar they are a matter of experience, may only be approached from a 1PP.

Later on, the term NOME has been introduced (Cardeña \& Facco, 2015; Facco, 2014; Facco et al., 2015) to encompass a wider series of experiences including both non-pathological ASCs and AEs, taking into account the above-mentioned definition of consciousness by William James. The term non-ordinary avoids tiling them to the concepts of normality vs. dysfunction; rather, it emphasizes their epistemological and metaphysical implications, i.e., their deviation from what is conventionally accepted. In other words, the concept of NOME includes the questions raised by their ostensible oddity and its relationship with the a priori adopted axioms and theories, an essential step for a proper method of study and interpretation. It is the same metaphilosophical 
problem implied in the study of the Self (Facco, Al khafaji, et al., 2019), which also calls for a metascientific approach overcoming the narrow positivist perspective of conventional medicine.

Following the Theorem of Incompleteness by Gödel (see Raatikainen, 2018 as a review), the limits of provability in formal axiomatic theories are now clear - i.e., single rigorous scientific discipline necessarily include statements which can neither be mathematically proved nor disproved. For example, the anthropic principle that has been included in astrophysics it is an extrascientific principle in itself connecting the "antecedent" and the "subsequent", the physical conditions and the biologic constraints (Carter, 1974, 2011; Rebaglia, 1996). Despite the application of Gödel's theorem to disciplines other than mathematics such as philosophy and neurosciences remains a matter of debate, it shows that one cannot reach the Galilean "mathematical certainty" despite allowing for a general success of biology and neuroscience (Buechner, 2010). When the subjective world is concerned, such a metaphilosophical and metascientific approach is more relevant than in neurobiology, since the 1PP and the meaning of the experience are the conditio sine qua non for a proper understanding, a fact calling for an interdisciplinary approach including psychology, philosophy and anthropology. According to Husserl, modern sciences are but a technical professional limited derivation of philosophy, to be meant as the world of reason and knowledge, while one must ask himself whether the objectivism of positive sciences may be a transcendental naivety (Husserl, 1970).

We have previously introduced the term NOMEs and partly dealt with them (Facco, 2018; Facco et al., 2015; Facco, Lucangeli, \& Tressoldi, 2018), but we have not provided a list of them so far. Table 4 and Figure 1 show the varieties of NOMEs and the main conditions able to favor or induce them.

Table 4: Non-Ordinary Mental Expressions

1) Alien abduction experiences

2) Experience of other identities

4) Hallucinations and visions:
a) Spontaneous
b) Hypnagogic \& hypnopompic hallucinations
c) Use of Hallucinogens and other psychotropic agents

4) Extrasensorial perception
a) Clairvoyance
b) Precognition, premonition
c) Retrocognition
d) Telepathy

5) Hypnosis

6) Lucid dreaming

7) Meditation

8) Mystical experiences

9) NDE

10) NDE-like

11) OBE

12) Psychokinesis: 
a) Macropsychokinesis (anomalous force)

b)Micropsychokinesis (anomalous perturbation)

13) Previous lives' memories

14) Synchronicity

15) Synesthesia

16) Stigmata

17) Superior states of consciousness:

a) Enlightenment

b)Epoptéia, according to Aristotle

c) Self enlargement acording to Russell (1912)

d)Self expansion beyond ordinary states, according to Arieti (1967)

e) Spiritual Self, according to James (1917)

f) Superconscious states according to Assagioli (1988)

18) Trance

19) Unexplained healing

20) Xenoglossy

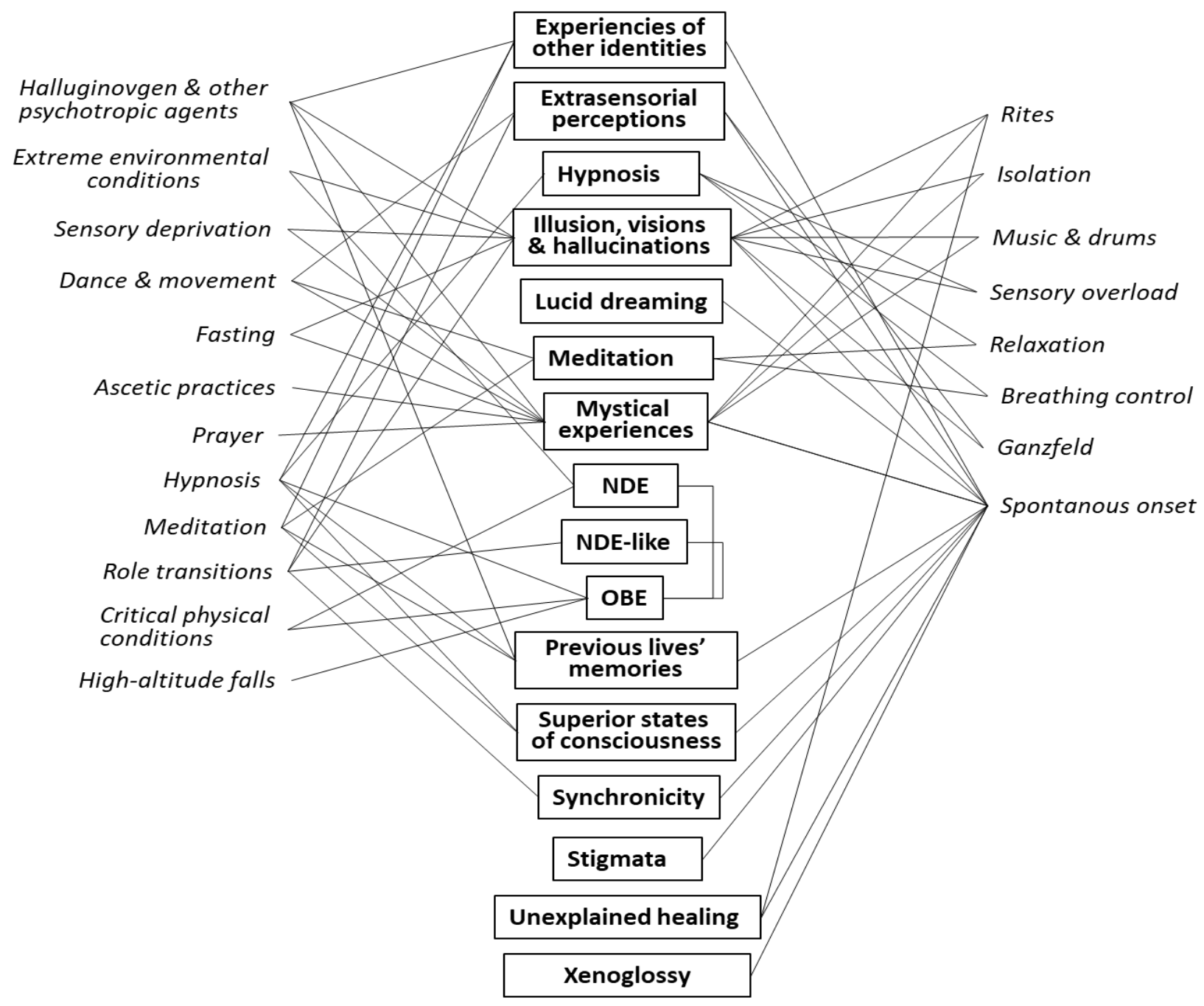

Figure 1: NOMEs and their main possible triggers and conditions (in Italics) in which they may occur. 
Of course, this is only a first, provisional outline susceptible to further changes. Metaphorically, it must not be considered as a hard rock, but rather, as the changeable sand of the watershore, where some NOMEs might be withdrawn and others added in the future, according to further evidence. In Table 4 they have been listed in alphabetic order refraining from classifying them on the base of their hypothesized nature (e.g., those of seemingly religious or parapsychological nature) or possible triggers, in order to avoid any a priori constraint and meet the fact that most of them may belong to more than one single category. For example, mystic experiences may be cataphatic or apophatic (Facco et al., 2018; Forman, 1998) - the former including visions belonging to specific denominations, the latter being marked by the absence of any image and, as such, independent from any specific belief and theology. Therefore, apophatic experiences share common elements with the tabula rasa of Meister Eckhart in Christian mystic tradition, the state of turiya in Veda, nirọ̣ha in Patañjali Yoga-Sütra and no-mind doctrine in Zen Buddhism and also include the meditation techniques allowing to reach this states (Facco, 2014, 2017). Equally, they may share some common aspects with NDEs, OBEs [the first of which in Christendom has been described by St. Paul in the Second Letter to the Corinthians (Facco, 2010,pp. 142-145)], and hallucinations, which have been traditionally considered a psychiatric phenomenon but may be experienced in up to $15 \%$ of non-clinical population (Bentall, 2014). Likewise, hypnosis and meditation share several common aspects and both of them may give raise both apophatic and cataphatic-like experiences viz., experiences of transcendent tonality associated to thriving imagination - while OBEs may easily be induced in highly hypnotizable subjects (Cardena, 2005; Cardena, Jonsson, Terhune, \& Marcusson-Clavertz, 2013; Facco, 2017; Facco, Casiglia, et al., 2019).

Hypnosis and meditation have been included in Figure 1 both as NOMEs and procedures of induction, according to previous reports (Barnier \& Nash, 2008; Facco, Testoni, et al., 2017). The term trance has been also included in the list of NOMEs only to mention a traditional term related to ASCs; as a matter of facts, it is a generic, ambiguous, ill-defined term which may be assigned to most NOMEs and will hopefully be withdrawn in the future, once the topic will be better understood.

Previous classifications of ASCs have skipped the superior states of consciousness; this is not surprising, since the traditional inclination of medicine is to seek for less-than-normal or pathologic phenomena while the ruling materialist perspective a priori refuses what looks "immaterial" and/or has the flavor of transcendence. Nevertheless, they are of paramount importance in the comprehension of the physiology of mind, the nature of Self - especially the so-called spiritual Self - as well as metacognitive development and achievement of perfection on the way of Jung's individuation up to the level of enlightenment, all facts regarding higher-order mind faculties. It is a crucial problem since time immemorial in both Eastern and Western cultures, including a proper understanding of:

a) The role of meditation and the concept of enlightenment.

b) The meaning of wisdom and sageness (a term the meaning of which has been lost in modern era);

c) The role of Greek mysteries in the achievement of a superior kind of knowledge and enlightenment, well defined by Aristotle himself with the term epoptéia (Eudemo, fr. 10, quoted by Scarpi, 2012).

d) The shamanic rituals and their use of psychotropic plants as a means of knowledge. 
e) The Spiritual Self according to William James, including his experience with nitrous oxyde (James, 1882, 1917).

f) The enlargement of Self (Arieti, 1967; Facco, Al khafaji, et al., 2019; Russell, 1912).

g) The superconscious according to Assagioli (1988).

The so-called superconscious may occur as a transient experience, may be favored by psychotropic drugs or persist and become a steady new basal condition following a long philosophical-practical training, as it may occur in expert meditators and reach its highest, apparently unattainable levels in the great enlightened men of the history.

Finally, we have included in the list of NOMEs some psi phenomena, for the sake of coherence with a rigorous but open-minded approach, taking into account their inescapable epistemological implications. Psi phenomena are traditionally considered a matter of parapsychology and, as such, usually discarded by scientific investigation, due to their ostensible oddity and incompatibility with the accepted axioms and theories. On the other hand, one must recognize that facts are never parapsychological in themselves: they may only be true or false. If so, science has the duty to falsify them (according to Popper, 1959) and, if proved to be false, they should be simply discarded, while, if shown to be true, they should be included in the accepted knowledge; should this be the case, it would imply an updating of the known laws of nature. In other words, a rigorous scientific study of these phenomena pertains to science, rather than parapsychology. Relegating them to the uncomfortable topic of parapsychology is a matter of prejudice rather than science: it pertains to the adopted or refused axioms and theories and not to facts in themselves, placing the problem on the plane of the relationship between orthodoxy and heresy.

The psi phenomena included in the list of NOMEs have been classified into two groups according to Cardeña (2018) as extrasensorial perceptions (ESP) and psychokinesis (PK), which have been investigated by several rigorous studies. The mentioned article by Cardeña summarizes the results of 11 meta-analyses of studies on ESP and PK for a total of over 1,600 subjects, supporting the following conclusions: a) it is possible to record these phenomena and check or disprove their reality; b) Psi phenomena cannot be easily replicated on demand and their effect sizes are small and, thus, call for appropriate statistical techniques; c) the available results suggest the reality of at least part of them and exclude they be yielded by methodological flaws; d) their proper understanding and interpretation is still lacking. Therefore, it is a duty of science to properly understand them.

\section{NOMEs and the mind-body-world relationship: physical and epistemogical implications}

Most NOMEs - such as like NDE, mystic experiences, vision and prophecies - suggest the idea of other worlds and/or a wider dimension of reality with respect of the ordinarily accepted one. The latter in turn depends on the zeitgeist and the adopted weltanschauung - at this time ruled by classical thought and materialist monism, especially in the world of biology and medicine. Therefore, the core of the problem in NOME interpretation is the lack of plausibility and ostensible incompatibility with respect to the accepted model of reality. In this regard, one must be aware that the foundation of positivism and materialism is metaphysical in nature, i.e., is based on undemonstrated axioms. If this is the case, it is a duty of both the philosopher and the scientist to constantly wonder about their truthfulness, as clearly emphasized by Aristotle himself (Metaphysics, 1005b, 1-5), in order to avoid dogmatic drifts. 
The ruling monist materialist stance of neuroscience can be considered as the long term result of the Descartes' error - i.e, the split of the mind-body unit resulting from the ontological separation between res cogitans and res extensa (Damasio, 1994; Facco \& Fracas, 2018; Facco, Lucangeli, et al., 2017) - as well as the Galilean mathematical apriorism at the foundation of modern sciences (Burtt, 2003). As Galileo stated in the Dialogue Concerning the Two Chief World Systems - Day First - "But taking man's understanding intensively, in so far as this term denotes understanding some proposition perfectly, I say that the human intellect does understand some of them perfectly, and thus in these it has as much absolute certainty as Nature itself has. Of such are the mathematical sciences alone; that is, geometry and arithmetic, in which the Divine intellect indeed knows infinitely more propositions, since it knows all. But with regard to those few which the human intellect does understand, I believe that its knowledge equals the Divine in objective certainty" (Galilei, 1632)

As a result, medicine - the most humanistic of Galilean sciences - more and more focused on the Cartesian bodily earthen machine neglected the soul (mind), being it ostensibly immaterial. Nevertheless, the different ontology of the res cogitans and the res extensa - and thus their incommensurability - is an ill-founded, abstract metaphysical principle, a sort of rationalistic guillotine, since they constitute an inseparable mind-body unit in vivo. Then, the mathematical, mechanist-reductionist fragmentation of the living being has reduced the subject to a reified body codified as a class of parametric equivalences - a small clock (e.g., the La Mettrie's Machine Man, 1747) surrounded by the big clock of Newtonian universe (an obsolete view in modern physics).

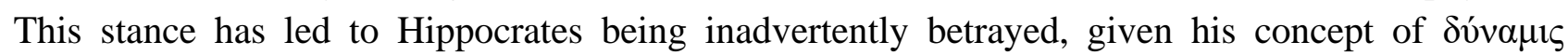
(dýnamis), viz., the inseparable union and interrelationship of mind-body-environment (Facco \& Tagliagambe, 2020). As previously reported (Facco et al., 2015; Facco \& Fracas, 2018; Facco, Lucangeli, et al., 2017), the arbitrary split of body and mind amounted to what has been named the original sin of Galilean sciences. In fact, the Descartes' radical dualism - assigning the soul to the exclusive competence of the Church and the body to the science - was a smart gimmick allowing for a compromise able to avoid an irreconcilable fracture between the Church and the nascent science.

In short, the new sciences, when applied to living beings, reduced them to a set of mathematical quantitative parameters, skipping all what was incompatible with them. They were also imbued with naïve realism, marked by Galileo overestimation of the absolute, divine certainty obtainable by mathematics and the Newton's abstract concepts of absolute and relative time and space, the definition of which - a hard job, if possible - was axiomatically drawn from the fact that "time, space, place, and motion are very familiar to everyone" (Newton, 1726, Definition 8, Scholium). It is worth noting that Newton, despite endorsing it, was not fully satisfied with the Descartes' mechanistic explanation of the world (its one-sidedness), a fact which led him to study alchemy for about 25 years (Schettino, 2017).

According to Aristotle, who in Metaphysics (1005b, 1-5) clearly warned that any rigorous demonstration remained a matter of $\delta o ́ \xi \alpha$ (dóxa, opinion, relative knowledge), the classical concepts of space, time and matter - as well as the concepts of present and simultaneity - have been demolished by theory of relativity and quantum physics. The principle of locality, strongly supported by Einstein - who held the hypothesis of hidden variables in the attempt to explain the spoeky actions at distance who considered quantum mechanics incomplete because through it the existence of entanglement, called "spooky actions ad distance", had to be assumed (Einstein, 
Podolsky, \& Rosen, 1935) - has also been overcome with the demonstration of entanglement by quantum physic, now applied a t quantum cryptography and quantum information teleportation (Aspect, Grangier, \& Roger, 1982; Fracas, 2017; Hill \& Cox, 2012; Moreau et al., 2019; Musser, 2015). A quantum biology is emerging in life sciences as well, while an increasing interest has raised on the hypothesis of quantum and/or quantum-like aspects of consciousness (Facco \& Fracas, 2018; Grinberg-Zylberbaum, Delaflor, Attie, \& Goswami, 1994; Poznanski, Tuszynski, \& Feinberg, 2017; Standish, Johnson, Kozak, \& Richards, 2003; Thaheld, 2010; Wackermann, Seiter, Keibel, \& Walach, 2003). In this regard, it is worth mentioning that the only scientists who rediscovered the relevance of subjectivity in science and devoted themselves to the study of consciousness in early $20^{\text {th }}$ century were quantum physicists, in an epoch where both psychology and neurology considered it unworthy of investigation.

From the above discussion, one can consider from a solid scientific base what has been previously named the "plausibility of implausible" (Facco, Lucangeli, et al., 2017). It stems from the fact that: a) we know much less than we are inclined to believe; b) we are inclined to impose our mental categories and a priori assumptions to the Nature, seeing and accepting only what is compatible with them.

Instead, the world is far from being reducible to phenomena as they appear to consciousness on the base of the adopted metaphysics, the use of dianoetic reason (mainly based on Aristotelian logic) and the resulting weltanschauung. It is a topic of huge complexity, which cannot be analyzed here (for further details see Facco et al., 2018; Facco, Lucangeli, et al., 2017). Nevertheless, it is worth providing a short list of relevant data showing how little we know and how the Nature, as Feynman stated, is "absurd" (Feynman, 1985), or, better, is absurd when observed through the prism of the classic thought:

a) The known universe is limited by the cosmologic horizon, 95\% of which is made of dark matter and energy.

b) The Poincaré conjecture, demonstrated by Perelman in 2003 (O'Shea, 2008), topologically considers the universe as a 3-sphere with 4 dimensions, while the string theory (experimentally unproven yet) considers up to 26 spatial dimensions (Fracas, 2017). Therefore, one might speculate that unperceivable physical dimensions may exist, which might make what has been considered as transcendent so far as "physically" located beyond our human horizon. Anyway, even in our ordinary four-dimensional world (three spatial coordinates plus time), our capacity to observe facts is limited by our sense organs and available measurement devices.

c) In quantum physics matter is no longer considered the primary manifestation of the physical world but rather an expression of the physical world directly related with the energy concentration: if so, materialist monism, which relies on the classical concept of matter, is physically obsolete now, besides being self-contradictory from metaphysical point of view (Facco \& Fracas, 2018; Facco, Lucangeli, et al., 2017; Fracas, 2017; Severino, 2016; Wilczek, 2010).

As far as NOMEs are concerned, they are subjective universal phenomena of human mind across the ages and cannot be a priori reduced to a matter of plain brain circuitry and its dysfunction by a narrow materialist-reductionist neurobiological perspective. Of course, understanding their neurocorrelates remains a relevant aspect, but, alone, it leads to subjective aspects being lost once the process of reduction to brain circuitry is accomplished. Even if the so-called hard 
problem(Chalmers, 2013; Popper, Lindahl, \& Arhem, 1993) has not been solved yet, NOMEs can be properly investigated according to the neurophenomenological approach introduced by Francisco Varela (Deplazes-Zemp, 2016; Rudrauf, Lutz, Cosmelli, Lachaux, \& Le Van, 2003; Varela, 1996), merging the $1 \mathrm{PP}$ and $3 \mathrm{PP}$ in a whole and taking in due account the meaning of experience. As mentioned above, they also call for a metascientific approach, i.e. a multidisciplinary perspective merging neurosciences, philosophy, anthropology and physics in a whole.

In this approach, there is also a place for religions, to be faced through a metareligiousmetaphilosophical approach including both Eastern and Western philosophies, anthropology and psychology (for further details on the reasons and method of this approach, see (Facco, Al khafaji, et al., 2019; Jullien, 2015; Pasqualotto, 2008). According to Frazer (2009, Ch. 37), religions, despite their different perspectives and methods, share the essential common purpose of science and philosophy, i.e., they represent the super-human effort to probe the great unsolved mysteries of life and death in a mostly unknown universe. Therefore, religion, when its philosophical aspects cleansed of dogmas and doctrinal inflexibilities are appraised, must be regarded as a valuable matter of knowledge of highest human values (Fung Yu-Lan, 1958). This also may help overcoming the century-old ostensible Western incompatibilities between science and religion (in this context limited to the Church), which have led to the ill-founded compromise of the Two Magisteria (Alberts, 1998; Facco et al., 2015; Gould, 1997). Indeed, religion and spirituality are an important, inescapable topic in medicine and psychology, despite misunderstood and disparaged by the materialist monist stance; in fact, the World Psychiatric Association and the World Health Organization have recognized their relevance for mental health and quality of life (MoreiraAlmeida, Sharma, van Rensburg, Verhagen, \& Cook, 2016).

If the above discussion is correct, the plausibility of the implausible is the routinely faced enigma when dealing with NOMEs - as well as many other fields of knowledge, like the frontiers of modern physics - which cannot be simply solved by neglecting what is ostensibly incompatible with the adopted weltanschauung and/or a priori constraining them within the established knowledge. Therefore, the core of the problem is epistemological in nature and a shift of paradigm is required to properly investigate them.

We hold a modified version of the theory of the Three Worlds by Eccles \& Popper (Popper \& Eccles, 1977) - where world 1 = physical reality, world 2 = mind-brain unit (the processor), and world 3 = the world of the products of mind, including science. This model (Facco \& Fracas, 2018, Ch. 3) considers the world we know as a co-creation of the physical reality and the mind, since we cannot leave out of consideration the role of the mind-brain (with its qualia, perceptual features and operative system) as a transducer between the outer and the inner world, the latter being a representation of the former. If so, the relationship mind-world and the related epistemological implications may be schematically represented as follows (Figure 2): 


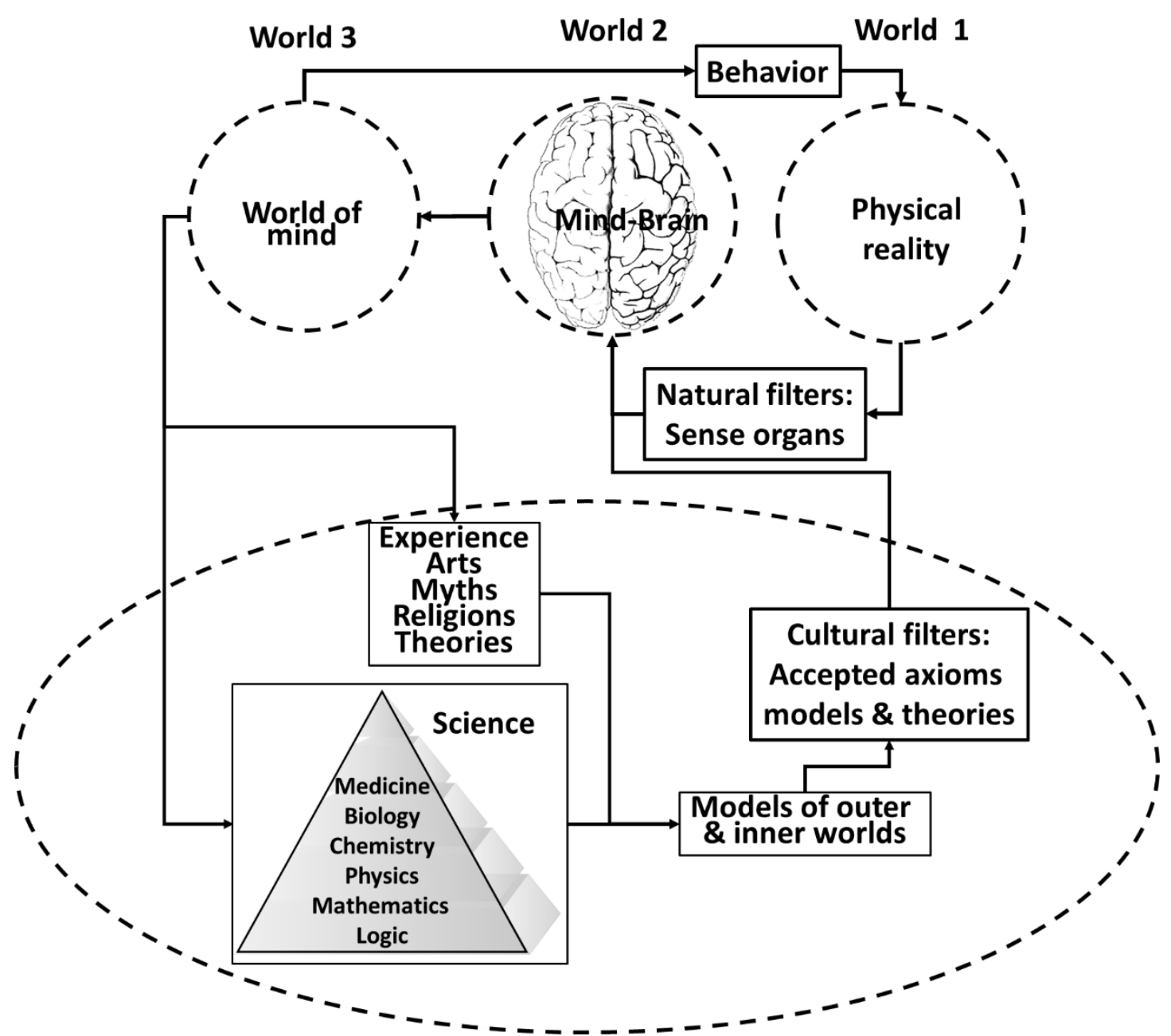

Figure 2: Schematic representation of the relationship between the outer world, the mind-brain unit, and the inner world, including the process of knowledge and the reciprocal influence between inputs from the outer world and its models.

The so-called pyramid of science belongs to the world 3, which in mainstream biology and medicine is based on classical physics and mathematics. Should quantum physics and chaos mathematics be added to orthodox ones, the outcome would undergo a huge change.

The whole of experience, scientific and non-scientific knowledge (including beliefs, accepted myths, and religious views) is the base to create models of the world, but, at the same time, they behave as cultural filters preventing to perceive and/or accept what is ostensibly incompatible with them. Likewise, sense organs - as any recording equipment (e.g., EEG) - have their own limits and filters, i.e., the band pass of recordable events.

As a result, the outer reality is known on the base of available information (always and necessarily a small part of it); furthermore, it is processed by the mind-brain operative system according to the limits imposed by sense organs, measuring instruments, and cultural filters dictated by the zeitgeist. The result of data processing only allows obtaining partial models of the relationships between facts. According to Metzinger \& Gallese (2003), the mind-brain is an intentional representational system, an ontological engine creating models of reality, starting from what is perceived and considered plausible. Anyway, models are not the reality in itself and, besides being necessarily partial, they belong to the world 3 (i.e., the "immaterial" world of consciousness), including science. 
The representation of reality may be biased by false judgements - like the Plato's bad archer in the Theaetetus (194a), shooting wide off the mark - a fact leading to erroneous models being developed; anyway, even good models of reality, being unavoidably partial, are doomed to be overcome.

Fortunately, science has the capacity to recognize errors, overcome the adopted models, and even self-reform by revising the adopted axioms and paradigm. This in turn leads to the weltanschauung being changed in an iterative process allowing for the improvement of knowledge.

The above analysis shows the process of knowledge as a dynamic, unceasing one, hopefully leading to errors being recognized and filtered out along time; if so, at any given time what we know is an inseparable mix of true and false propositions, the latter to be hopefully recognized and removed by further investigations. In this process, there is a high risk to filter out also real facts, when they are ostensibly incompatible with the ruling zeitgeist. This is more likely to occur when dealing with subjective phenomena - especially with NOMEs - given the ruling materialist stance of science, in turn stemming from the axioms accepted since the beginning of modern science in $17^{\text {th }}$ century and never reappraised by mainstream medicine and biology. It is worth underscoring that medicine and psychology denied the relevance of consciousness in early $20^{\text {th }}$ century: paradoxically, quantum physicists (i.e., the scientists devoted par excellence to the study of the physical world) were the first who rediscovered the relevance of subjectivity in science in the general indifference of scientists competent in the study of human mind and brain.

NOMEs may show a link with psychiatric and neurological disorders, as correctly emphasized by Ludwig, but this is not a good reason to paint all of them with a broad brush: the common aspects may help shedding light in those physiological processes, of which the pathological ones are the uncontrolled dysfunction. Neuropsychology is full of examples of these cases, like the relationship between speech and aphasias; as far as NOMEs are concerned, a similar link exists between the non-pathological experience of other identities and dissociative identity disorders (Facco, Mendozzi, et al., 2019). On the other hand, some NOMEs may be regarded as better-than-normal conditions, i.e., meditation, hypnosis and superior state of consciousness: this is a topic of paramount importance, given their potentially relevant role in both medicine and psychology. Of course, the differential diagnosis between physiological and pathological condition remains a step of paramount importance. The essential criterion for their proper evaluation had been already stated by Plato in the Phaedrus (265a): "[Socrates] And of madness there were two kinds; one produced by human infirmity, the other was a divine release of the soul from the yoke of custom and convention". The latter wisely emphasizes what looks odd despite reflecting better-than-normal faculties of human mind and valuable cognition. They have imbued the whole history of arts, philosophy, religion, and science, the latter being marked by Kuhn's scientific revolutions (Kuhn, 1962): without the Plato's divine release Einstein's great intuitions on relativity as well as the revolution introduced by quantum physics would not have been possible. Missing them due to a narrow, exclusivist materialist-reductionist perspective would lead to higher-order non-ordinary expressions of human mind being mistaken and lost forever. 


\section{References}

Alberts, B. (1998). Science and creationism. A view from the National Academy of Sciences. Preface. In National Academy of Sciences Staff. (pp. viii-ix). Washington: National Academic Press.

Arieti, S. (1967). The intrapsychic self: Feeling, cognition, and creativity in health and mental illness. New York, NY: Basic Books.

Aspect, A., Grangier, P., \& Roger, G. (1982). Experimental Realization of Einstein-PodolskyRosen-Bohm Gedankenexperiment : A New Violation of Bell's Inequalities. Physical Review Letters, 49(2), 91-94. https://doi.org/10.1103/PhysRevLett.49.91

Assagioli, R. (1988). Transpersonal Development. (2007th ed.). Forres, Scotland: Smilin Wisdom, imprint of Inner Way Productions.

Banzato, C. E., Mezzich, J. E., \& Berganza, C. E. (2005). Philosophical and methodological foundations of psychiatric diagnosis. Introduction. Psychopathology, 38(0254-4962 (Print)), $159-161$.

Barnier, A. J., \& Nash, M. R. (2008). Introduction: a roadmap for explanation, a working definition. In M. R. Nash \& A. J. Barnier (Eds.), The Oxford handbook of hypnosis. (p. 18). New York: Oxford University Press.

Bentall, R. P. (2014). Hallucinatory experience. In E. Cardena, S. Lynn J., \& S. Krippner (Eds.), The varieties of anomalous experience: Examining the scientific evidence. (Vol. 2nd, pp. 109143). Washington: American Psychologcal Association.

Berganza, C. E., Mezzich, J. E., \& Pouncey, C. (2005). Concepts of disease: their relevance for psychiatric diagnosis and classification. Psychopathology, 38(0254-4962 (Print)), 166-170.

Boveroux, P, Bonhomme, V., Boly, M., Vanhaudenhuyse, A., Maquet, P., \& Laureys, S. (2008). Brain function in physiologically, pharmacologically, and pathologically altered states of consciousness. Int.Anesthesiol.Clin., 46(1537-1913 (Electronic)), 131-146.

Boveroux, Pierre, Bonhomme, V., Boly, M., Vanhaudenhuyse, A., Maquet, P., \& Laureys, S. (2008). Brain function in physiologically, pharmacologically, and pathologically altered states of consciousness. International Anesthesiology Clinics, 46(3), 131-146. https://doi.org/10.1097/AIA.0b013e318181a8b3

Buechner, J. (2010). Are the Godel incompleteness theorems limitative results for the neurosciences? J Biol.Phys., 36(1573-0689 (Electronic)), 23-44.

Burtt, E. A. (2003). The Metaphysical Foundation of Modern Science. Mineaola, NY, US: Dover Publications.

Cardena, E. (2005). The phenomenology of deep hypnosis: quiescent and physically active. Int.J Clin.Exp.Hypn., 53(0020-7144 (Print)), 37-59.

Cardeña, E. (2018). The experimental evidence for parapsychological phenomena: A review. 
American Psychologist, 73(5), 663-677. https://doi.org/10.1037/amp0000236

Cardeña, E., \& Facco, E. (2015). Non-Ordinary Mental Expressions. Lausanne, CH: Frontiers Media SA.

Cardena, E., Jonsson, P., Terhune, D. B., \& Marcusson-Clavertz, D. (2013). The neurophenomenology of neutral hypnosis. Cortex, 49(1973-8102 (Electronic)), 375-385.

Cardeña, E., Lynn J., S., \& Krippner, S. (Eds.). (2004). Varieties of Anomalous Experiences (1st ed.). Washington D.C., USA: American Psychological Association.

Cardeña, E., Lynn J., S., \& Krippner, S. (Eds.). (2014). Varieties of Anomalous Experiences. (2nd ed.). Washington,DC, USA: American Psychological Association.

Carter, B. (1974). Large Number Coincidences and the Anthropic Principle in Cosmology. In M. S. Longair (Ed.), Confrontation of Cosmological Theories with Observational Data. (pp. 291 298). Dordrecht, The Netherlands.: Reidel.

Carter, B. (2011). Republication of: Large number coincidences and the anthropic principle in cosmology. General Relativity and Gravitation, 43(11), 3225-3233. https://doi.org/10.1007/s10714-011-1258-7

Chalmers, D. J. (2013). How can we construct a science of consciousness? Ann.N.Y.Acad.Sci., 1303(1749-6632 (Electronic)), 25-35.

Charland-Verville, V., Jourdan, J.-P., Thonnard, M., Ledoux, D., Donneau, A.-F., Quertemont, E., \& Laureys, S. (2014). Near-death experiences in non-life-threatening events and coma of different etiologies. Frontiers in Human Neuroscience, 8, 203. https://doi.org/10.3389/fnhum.2014.00203

Damasio, A. (1994). Descartes' error. New York: G.P. Putnam.

Deplazes-Zemp, A. (2016). Artificial Cell Research as a Field that Connects Chemical, Biological and Philosophical Questions. Chimia (Aarau.), 70(0009-4293 (Print)), 443-448.

Dijksterhuis, A., \& Nordgren, L. F. (2006). A Theory of Unconscious Thought. Perspect.Psychol Sci., 1(1745-6916 (Print)), 95-109.

Einstein, A., Podolsky, B., \& Rosen, N. (1935). Can Quantum-Mechanical Description of Physical Reality Be Considered Complete? Physical Review, 47, 777-780.

Facco, E. (2010). Esperienze di premorte. Scienza e coscienza ai confini tra fisica e metafisica. Lungavilla (PV): Edizioni Altravista.

Facco, E. (2014). Meditazione e Ipnosi tra neuroscienze, filosofia e pregiudizio. Lungavilla, PV, Italy: Altravista.

Facco, E. (2017). Meditation and Hypnosis: Two Sides of the Same Coin? International Journal of Clinical and Experimental Hypnosis, 65(2), 169-188. https://doi.org/10.1080/00207144.2017.1276361

Facco, E. (2018). Ipnosi ed esperienze di premorte nel continuum delle espressioni non ordinarie 
della mente. IPNOSI, (1), 13-38. https://doi.org/10.3280/IPN2018-001002

Facco, E., \& Agrillo, C. (2012a). Near-death-like experiences without life-threatening conditions or brain disorders: A hypothesis from a case report. Frontiers in Psychology, 3(art. 490), 1-6. https://doi.org/10.3389/fpsyg.2012.00490

Facco, E., \& Agrillo, C. (2012b). Near-death experiences between science and prejudice. Frontiers in Human Neuroscience, 6(art. 209), 1-7. https://doi.org/10.3389/fnhum.2012.00209

Facco, E., Agrillo, C., \& Greyson, B. (2015). Epistemological implications of near-death experiences and other non-ordinary mental expressions: Moving beyond the concept of altered state of consciousness. Medical Hypotheses, 85(1), 85-93.

https://doi.org/10.1016/j.mehy.2015.04.004

Facco, E., Al khafaji, B. E., \& Tressoldi, P. (2019). In search of the true self. Journal of Theoretical and Philosophical Psychology, 39(3), 157-180. Retrieved from http://dx.doi.org/10.1037/teo0000112

Facco, E., Casiglia, E., Al Khafaji, B. E., Finatti, F., Duma, G. M., Mento, G., ... Tressoldi, P. (2019). The neurophenomenology of out-of-body experiences induced by hypnotic suggestions. International Journal of Clinical and Experimental Hypnosis, 67(1), 39-68. https://doi.org/10.1080/00207144.2019.1553762

Facco, E., Casiglia, E., Zanette, G., \& Testoni, I. (2017). On the way of liberation from suffering and pain: role of hypnosis in palliative care. Ann.Palliat.Med., (2224-5839 (Electronic)), 1-12. Retrieved from http://apm.amegroups.com/article/view/14986

Facco, E., \& Fracas, F. (2018). L'enigma della coscienza. Milano: Mondadori.

Facco, E., Lucangeli, D., \& Tressoldi, P. (2017). On the Science of Consciousness: Epistemological Reflections and Clinical Implications. EXPLORE: The Journal of Science and Healing, 13(3), 163-180. https://doi.org/10.1016/j.explore.2017.02.007

Facco, E., Lucangeli, D., \& Tressoldi, P. (2018). Dr. A.M. - A rare case of a modern Mystic? Implications for Psychology and Medicine. Spirituality in Clinical Practice, 1-22. Retrieved from http://dx.doi.org/10.1037/scp0000171

Facco, E., Mendozzi, L., Bona, A., Motta, A., Garegnani, M., Costantini, I., ... Lipari, S. (2019). Dissociative identity as a continuum from healthy mind to psychiatric disorders: epistemological and neurophenomenological implications approached through hypnosis. Medical Hypotheses, 130(109274). https://doi.org/10.1016/j.mehy.2019.109274

Facco, E., \& Tagliagambe, S. (2020). Ritornare a Ippocrate. Riflessioni sulla medicina di oggi. Milano, Italy: Mondadori.

Facco, E., Testoni, I., Ronconi, L., Casiglia, E., Zanette, G., \& Spiegel, D. (2017). Psychological Features of Hypnotizability: A First Step Towards Its Empirical Definition. International Journal of Clinical and Experimental Hypnosis, 65(1), 98-119. https://doi.org/10.1080/00207144.2017.1246881

Feynman, R. P. (1985). QED: The Strange Theory of Light and Matter. Princeton: Princeton 
University Press.

Forman, R. C. K. (1998). What does mysticism have to teach us about consciousness? J.Consciousness Studies, 5(2), 185-201.

Fracas, F. (2017). Il mondo secondo la fisica quantistica. Segrate (Mlano): Sperling \& Kupfer.

Frances, A. (2014). Saving Normal: An Insider's Revolt against Out-of-Control Psychiatric Diagnosis, DSM-5, Big Pharma, and the Medicalization of Ordinary Life. New York, NY, USA: William Morrow Paperbacks.

Frazer, J. G. (2009). The Golden Bough. A Study in Magic and Religion. Oxford: Oxford University Press.

Fung Yu-Lan. (1958). A Short History of Chinese Philosophy. New York, NY, USA: The Macmillan Company. Retrieved from https://archive.org/details/in.ernet.dli.2015.260423/page/n1

Galilei, G. (1632). Dialogue Concerning the Two Chief World Systems: Ptolemaic \& Copernican. Oakland, CA, US: University of California Press, 1967.

Gould, S. J. (1997). Nonoverlapping magisteria. Nat.Hist., 16(3), 16-22.

Grinberg-Zylberbaum, J., Delaflor, M., Attie, L., \& Goswami, A. (1994). The Einstein-PodolskyRosen paradox in the brain: the transferred potential. Physics Essays, 7(4), 422-428.

Hill, J. M., \& Cox, B. J. (2012). Einstein's special relativity beyond the speed of light. Proc. R. Soc. A, 468, 4174-4192. https://doi.org/10.1098/rspa.2012.0340

Husserl, E. (1970). The Crisis of European Sciences and Transcendental Phenomenology: An Introduction to Phenomenological Philosophy. Evanstone: Northwestern University Press.

James, W. (1882). The Subjective Effects of Nitrous Oxyde. Mind, 7. Retrieved from https://ebooks.adelaide.edu.au/j/james/william/nitrous/

James, W. (1917). The Varieties of Religious Experience. A Study in Human Nature. (Kindle Edi). New York, NY, USA: Longmans, Green, \& Co.

Jaynes, J. (1990). The origin of consciousness in the breakdown of the bicameral mind. . Boston: Houghton Mifflin.

Jaynes, J. (2014). La natura diacronica della coscienza. MIlano: Adelphi.

Jullien, F. (2015). De l'Etre au Vivre. Lexique eurochinoise de la pensée. Paris, France: Gallimard.

Kingsley, P. (1999). In the dark places of wisdom. Poin Reyes, California: The Golden Sufi Center.

Kuhn, T. S. (1962). The structure of scientific revolutions. Chicago: University of Chicago Press.

La Mettrie, O. J. (1747). Machine Man and Other Writings. ( ridge T. in the H. Of, Ed.). Cambridge, UK: Cambridge University Press, 1996.

Ludwig, A. M. (1966). Altered states of consciousness. Arch.Gen.Psychiatry, 15(0003-990X (Print)), 225-234. 
Madden, K. (1994). Teresa of Avila: The will and the weaving. Journal of Religion and Health, 33(2), 131-147. https://doi.org/10.1007/BF02354533

Meister Eckhart. (2012). Dell'uomo nobile. MIlano: Adelphi.

Metzinger, T., \& Gallese, V. (2003). The emergence of a shared action ontology: building blocks for a theory. Conscious. Cogn, 12(1053-8100 (Print)), 549-571.

Moreau, P.-A., Toninelli, E., Gregory, T., Aspden, R. S., Morris, P. A., \& Padgett, M. J. (2019). Imaging Bell-type nonlocal behavior. Science Advances, 5(7), eaaw2563. https://doi.org/10.1126/sciadv.aaw2563

Moreira-Almeida, A., Sharma, A., van Rensburg, B. J., Verhagen, P. J., \& Cook, C. C. (2016). WPA Position Statement on Spirituality and Religion in Psychiatry. World Psychiatry, 15(1723-8617 (Print)), 87-88.

Musser, G. (2015). Spooky Action at a Distance. New York, NY, USA: Scientific American / Farrar, Straus and Giroux.

Newton, I. (1726). The Principia: The Authoritative Translation and Guide: Mathematical Principles of Natural Philosophy. Oakland, CA, US: University of California press, 2016.

O'Shea, D. (2008). The Poincare Conjecture: In Search of the Shape of the Universe. London, UK: Walker Books.

Pasqualotto, G. (2008). East \& West. Venice, Italy: Marsilio Editori.

Plum, F., \& Posner, J. B. (1980). The Diagnosis of Stupor and Coma. Philadelphia, US: FA Davis $\&$ Co.

Popper, K. R. (1959). The logic of scientific discovery. London: Hutchinson.

Popper, K. R., \& Eccles, J. C. (1977). The Self and His Brain. Berlin: Springer-Verlag.

Popper, K. R., Lindahl, B. I., \& Arhem, P. (1993). A discussion of the mind-brain problem. Theor.Med., 14(0167-9902 (Print)), 167-180.

Poznanski, R. R., Tuszynski, J. A., \& Feinberg, T. E. (2017). Biophysics of Consciousness. London, UK: World Scientific Publishing Co. Pte Ltd.

Raatikainen, P. (2018). Gödel's Incompleteness Theorems. In E. N. Zalta (Ed.), The Stanford Encyclopedia of Philosophy (pp. 1-68). Stanford, CA, USA: University of Stanford, CA, US.

Rebaglia, A. (1996). Critica della ragione metascientifica. Milano: Franco Angeli.

Revonsuo, A., Kallio, S., \& Sikka, P. (2009). What is an altered state of consciousness? Philosophical Psychology, 22(2), 187-204. https://doi.org/10.1080/09515080902802850

Ritter, S. M., \& Dijksterhuis, A. (2014). Creativity-the unconscious foundations of the incubation period. Front Hum.Neurosci., 8(1662-5161 (Linking)), 215.

Rudrauf, D., Lutz, A., Cosmelli, D., Lachaux, J. P., \& Le Van, Q. M. (2003). From autopoiesis to neurophenomenology: Francisco Varela's exploration of the biophysics of being. Biol.Res., 
36(0716-9760 (Print)), 27-65.

Russell, B. (1912). Problems of Philosophy. Oxford, UK: Oxford University Press.

Scarpi, P. (2012). Le religioni dei misteri. (Vol. VI). Milano: Mondadori.

Schettino, V. (2017). Isaac Newton and Alchemy. Substantia, 1(1), 69-76. https://doi.org/10.13128/Substantia-12

Severino, E. (2016). The Essence of Nihilism. Brooklin, NY: Verso.

Standish, L. J., Johnson, L. C., Kozak, L., \& Richards, T. (2003). Evidence of correlated functional magnetic resonance imaging signals between distant human brains. Altern.Ther.Health Med, 9(1078-6791 (Print)), 122-128,125,128.

Thaheld, F. H. (2010). Quantum Nonlocality: Does Nature also Perform the Trick Via a Biological Route? NeuroQuantology, 8(2), 164-167. Retrieved from https://www.neuroquantology.com/index.php/journal/article/view/282/280

Tressoldi, P., Facco, E., \& Lucangeli, D. (2017). On the primacy and irreducible nature of firstperson versus third-person information. FR1000Research, 6(99), 1-32. https://doi.org/10.12688/f1000research.10752.3

Vaitl, D., Birbaumer, N., Gruzelier, J., Jamieson, G. A., Kotchoubey, B., Kubler, A., ... Weiss, T. (2005). Psychobiology of altered states of consciousness. Psychol.Bull., 131(0033-2909), 98127.

Varela, F. J. (1996). Neurophenomenology: a methodological remedy to the hard problem. J.Consc.Studies, 3, 330-350.

Vecchio, L. (2004). Filosofi e Medici. Pozzuoli: Naus Editoria.

Wackermann, J., Seiter, C., Keibel, H., \& Walach, H. (2003). Correlations between brain electrical activities of two spatially separated human subjects. Neurosci.Lett., 336(0304-3940), 60-64.

Wakefield, J. C. (2010). Misdiagnosing normality: Psychiatry's failure to address the problem of false positive diagnoses of mental disorder in a changing professional environment. $J$ Ment.Health, 19(1360-0567 (Electronic)), 337-351.

Watters, E. (2011). Crazy Like Us: The Globalization of the American Psyche. London, UK: Robinson Publishing.

Wilczek. (2010). The Lightness of Being. Mass, Ether, and the Unification of Forces. (B. Books, Ed.). New York, NY. 